\title{
POROSITY CLUSTERS AND RECRYSTALLIZATION IN SINGLE-CRYSTAL COMPONENTS
}

\author{
D. Goldschmidt*, U. Paul** and P.R. Sahm** \\ *Motoren- und Turbinen-Union München GmbH \\ Dachauer Straße 665, 8000 München 50 \\ ${ }^{* *}$ Gießerei-Institut Aachen, Intzestraße 5, 5100 Aachen
}

\begin{abstract}
The influence of cross-section transients on dendritic single-crystal growth in the presence of asymmetric heat flux was investigated for CMSX-6 and SRR99, two nickel-base superalloys. The probability of the formation of porosity clusters is largely dependent on the curvature of the solidification front, which in turn depends on the geometrical arrangement of the cluster and on the withdrawal rate. The proneness to recrystallization during $\gamma^{\prime}$-solutioning at the cross-scction transicnts duc to casting-induced deformations and misaligned dendritic growth was also examined. Recrystallization remains confined to the highly deformed areas as long as microstructural inhomogeneities, e.g. eutectics, are present during the heat treatment. HCF-testing established that these kinds of defects (porosity clusters as well as recrystallized grains) reduce the fatigue strength to about one half of that of defect-free material.
\end{abstract}




\section{$\underline{\text { Introduction }}$}

Single-crystal specimens for mechanical testing generally are manufactured from slabs or round bars with constant cross-sections, often solidified under laboratory conditions with high temperature gradients and axisymmetric heat flux. Actual single-crystal components, however, such as blades and vanes for gas turbines, are cast in large moulds of usually more than 20 parts [1]. Consequently, gradients are lowered and heat flux becomes asymmetric. Abrupt variations in cross-section (inner/outer shroud, core configuration, root-airfoil transition) often result in extensive porosity clusters where feeding is hindered $[2,3]$, or in recrystallization during $\gamma^{\prime}$-solutioning heat treatment duc to casting-induced deformations and internal stresses [4]. Blade and vane design is dictated by the components' functions, i.e. by aerodynamic, strength and weight considerations. Design modifications to fulfill casting requirements often result in lower performance. Therefore, it is essential to optimize the casting process with the objective of avoiding recrystallization and porosity clusters or of relocating them into regions of lower stress. This demands a comprehensive understanding of the mechanisms leading to recrystallization and porosity clusters and the methods of overcoming them, as well as the knowledge of their influence on mechanical properties. Presented here are the summarized findings of a detailed study whose objective it was to contribute to this subject.

\section{$\underline{\text { Experimental procedure }}$}

\section{Solidification experiments}

The influence of cross-section transitions on dendritic single-crystal growth in the presence of asymmetric heat flux was investigated in experiments similar to the production process. For this reason two different specimen types (dummies) with typical turbine blade geometries were designed (Figure 1).

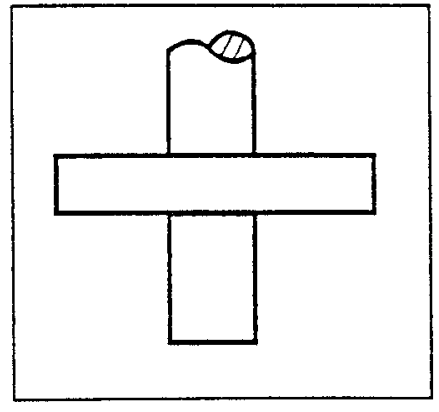

(a)

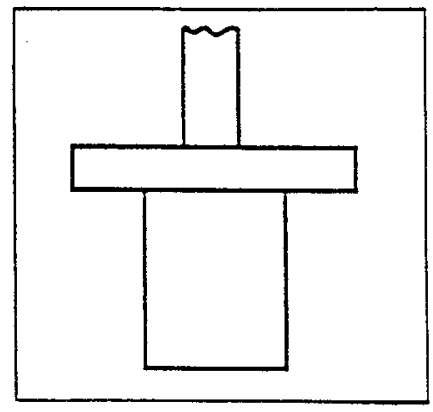

(b)

$$
\mid 1 \mathrm{~cm}
$$

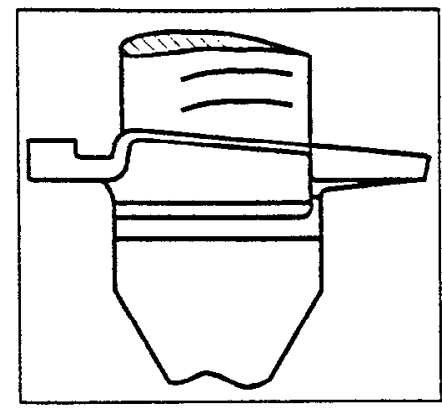

(c)

Figure 1: Two dummy geometries $(\mathrm{a}, \mathrm{b})$ with cross-section transitions similar to actual turbine blades (c) used for single-crystal solidification experiments

Four of these dummies, each featuring shroud-like cross-section transitions were assembled around a central runner rod to form a cluster. Ceramic moulds were manufactured by investement process. A specific number of thermocouples was placed at closely defined positions in the platform region. Two materials - SRR99 and CMSX-6 - were solidified as 
single crystals at different withdrawal rates $(1 ; 2 ; 3 ; 4 ; 5 ; 7,5$ and $10 \mathrm{~mm} / \mathrm{min})$ and specimen alignments. The temperature distribution was measured during unidirectional heat- extraction so that the passage of the solidification front (liquidus-isotherm for SRR99 $=1356^{\circ} \mathrm{C}$, for CMSX $-6=1331^{\circ} \mathrm{C}$ ) through the platform could be calculated. The solidified dummies were inspected metallographically and by $\boldsymbol{\gamma}$-diffractometric measurement. Microstructural characteristics such as dendritic alignment, low-angle boundaries, microporosity and recrystallized grains were correlated with the local solidification conditions in the platform region. The results have been verified by single-crystal solidification experiments with actual turbine blades (compare with Figure 1).

\section{Heat treatment experiments}

The influence of the $\gamma^{\prime}$-solutioning heat treatment on recrystallization was investigated by experimentation. CMSX- 6 specimen rods with surface deformations produced by a hardness tester or by blasting within closely defined parameters were heat treated at various temperatures. The recrystallized volume or the mean thickness of the recrystallized layer were determined by metallographic inspection of the transversal cross-section. This was then correlated to the microstructure produced during heat treatment (level of $\boldsymbol{\gamma}^{\prime}$-solutioning as well as presence of residual eutectic, porosity and incipient melting).

\section{Mechanical testing}

The high-cycle fatigue properties of CMSX-6 in the presence of recrystallized grains or extensive porosity were determined in tests at $850^{\circ} \mathrm{C}$, using specially prepared specimens. Porosity clusters were produced in near-net shape specimens by laying them flat (instead of upright) during directional solidification (Figure 2a). Well-defined recrystallized areas were produced in near-net shape specimens by deforming their surfaces with a hardness tester prior to heat treatment (Figure $2 b$ ).

(a)

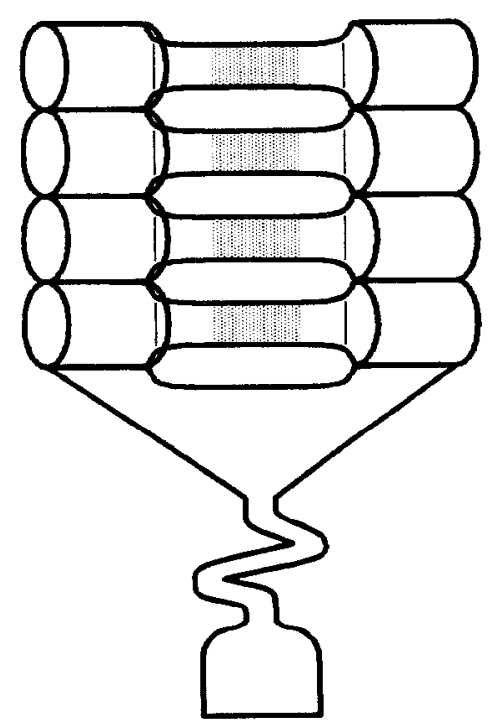

(b)

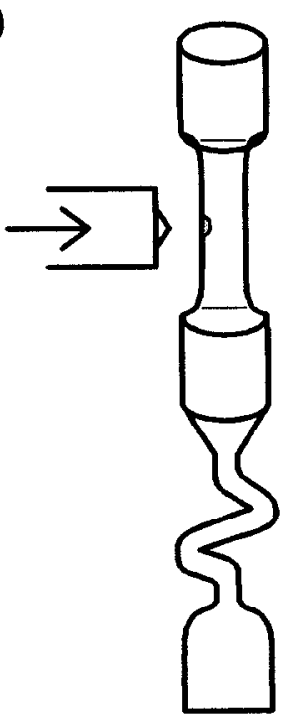

Figure 2: Production of specimens with porosity clusters (a) and recrystallized grains (b) 


\section{Results}

\section{Single-crystal growth at platform transitions}

The root-to-platform transition in turbine blades is critical with respect to single-crystal growth. Position and curvature of the liquidus isotherm in this area depend strongly on withdrawal rate [5] as well as the platform's and cluster's blockage of radiation from the heater or to the baffle. Ceramic accumulations in the transient region also influence heat transfer. Generally, as the withdrawal rate increases, the solidification front shifts from the heater region to the baffle. This alters the front's overall curvature from convex to concave.

There is a difference between platform regions facing the central runner (inner section) and regions facing the graphite heater (outer section) in the mould assembly (Figure 3).

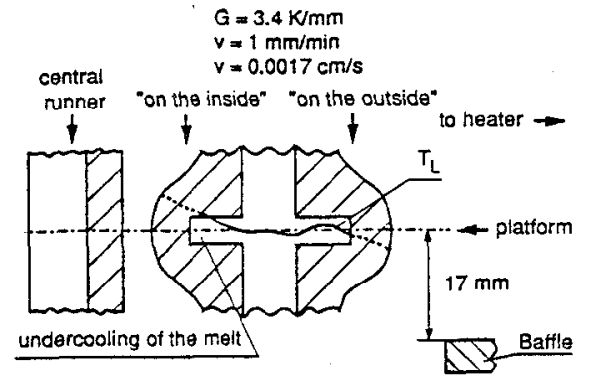

(a)

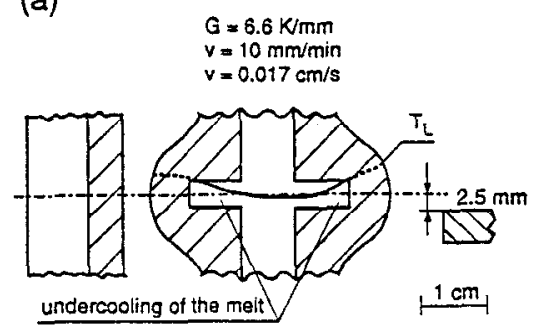

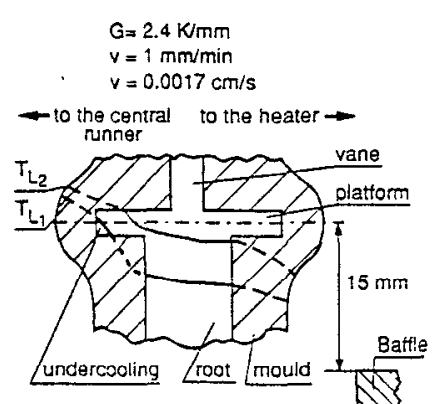

(b)

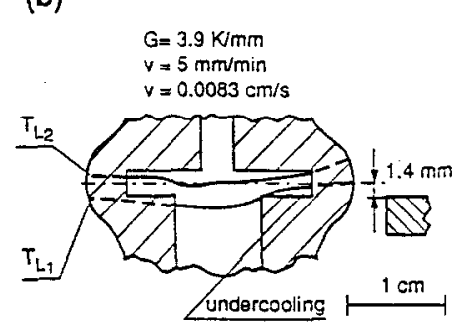

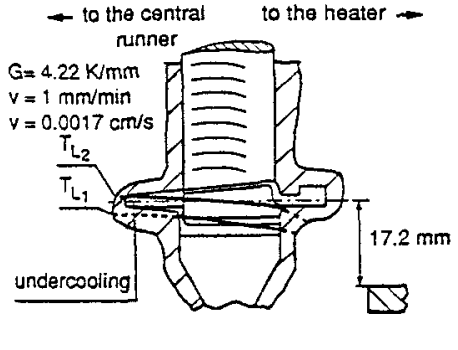

(c)

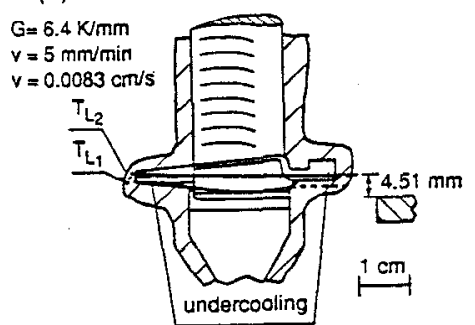

Figure 3: Position and curvature of the SRR99 liquidus isotherm $\left(T_{L}=1356^{\circ} \mathrm{C}\right)$ during passage through the platforms of the dummy $(\mathrm{a}, \mathrm{b})$ as well as the actual turbine blades (c) at different withdrawal rates

A slow withdrawal rate (1 to $2 \mathrm{~mm} / \mathrm{min}$ ) causes a slightly concave liquidus isotherm in platform regions facing the central runner and a convex curvature in regions facing the graphite heater. Both inner and outer regions show a concave curvature of the liquidus isotherm at high withdrawal rates ( 5 to $10 \mathrm{~mm} / \mathrm{min}$ ).

If the curvature is concave, the temperature in the platform edge falls below the liquidus temperature, and the dendrite tips from the rod are unable to reach this region. Either heterogeneous nucleation occurs or, if possible, the melt is undercooled until the solidification front has advanced far enough for dendrites to grow from the rod into the platform. For SRR99 and CMSX-6 a maximum undercoolability in the applied ceramic shell system (silicasol binder and ahımina refractory material) of $17 \mathrm{~K}$ and $27 \mathrm{~K}$, respectively, has been measured. Therefore, a slight undercooling does not cause any loss of single-crystallinity in the outer platform regions. The local temperature gradient changes its dircction (thermally undercooled melt) and leads to rapid lateral growth of secondary dendrites (Figure 4). 

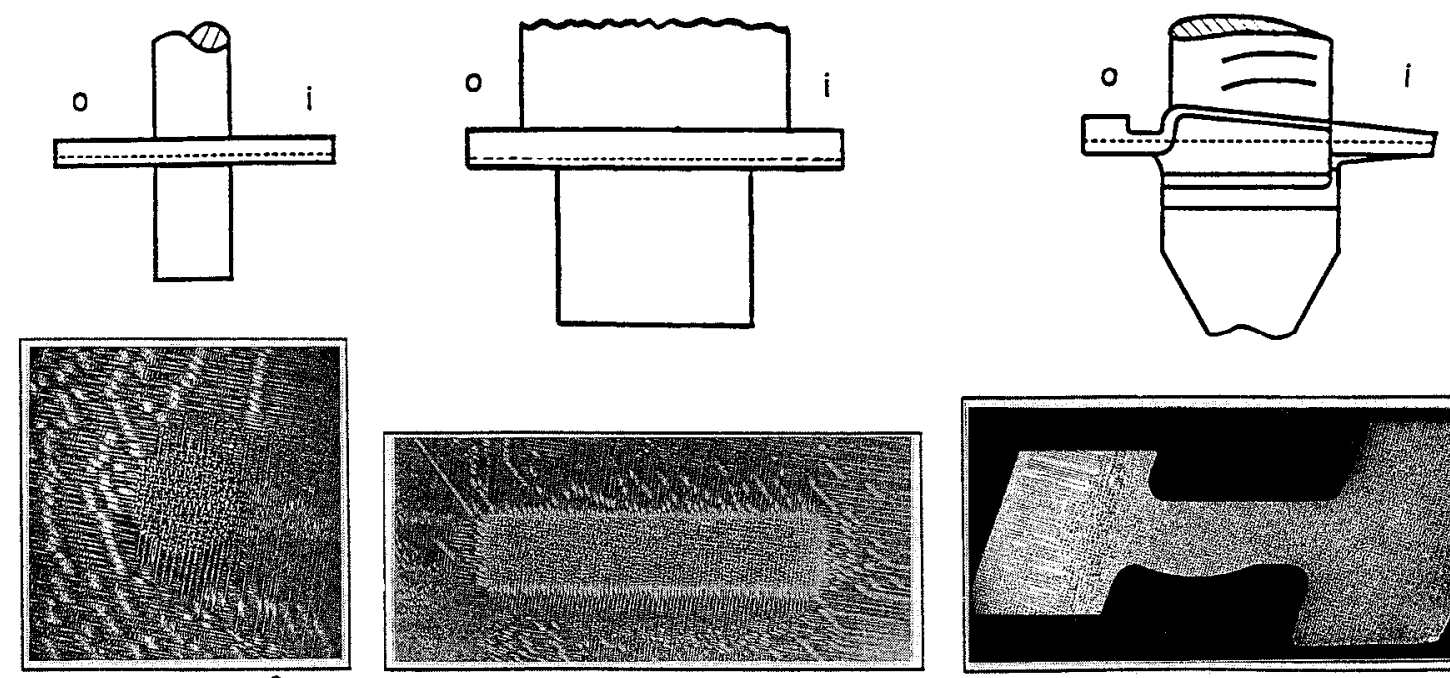

(a)
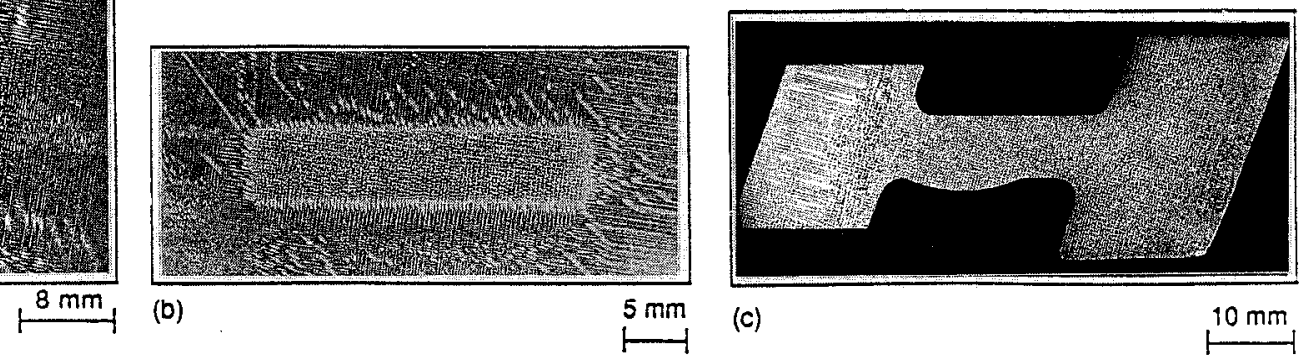

(c)

$10 \mathrm{~mm}$

Figure 4: Dendritic structure in cross-section transitions of dummy (CMSX-6; a, b) and actual turbine blades (SRR99; c) characterized by rapid lateral dendrite growth

Depending on the degree of undercooling ( 3 to $20 \mathrm{~K}$ ) growth rates of 30 to $120 \mathrm{~mm} / \mathrm{min}$ have been measured [6]. This lateral growth is characterized by a striation of the secondary dendrites, visible on the platform's lower surface. The high amount of latent heat released during this growing phase results in recalescence in the undercooled platform regions (Figure 5).
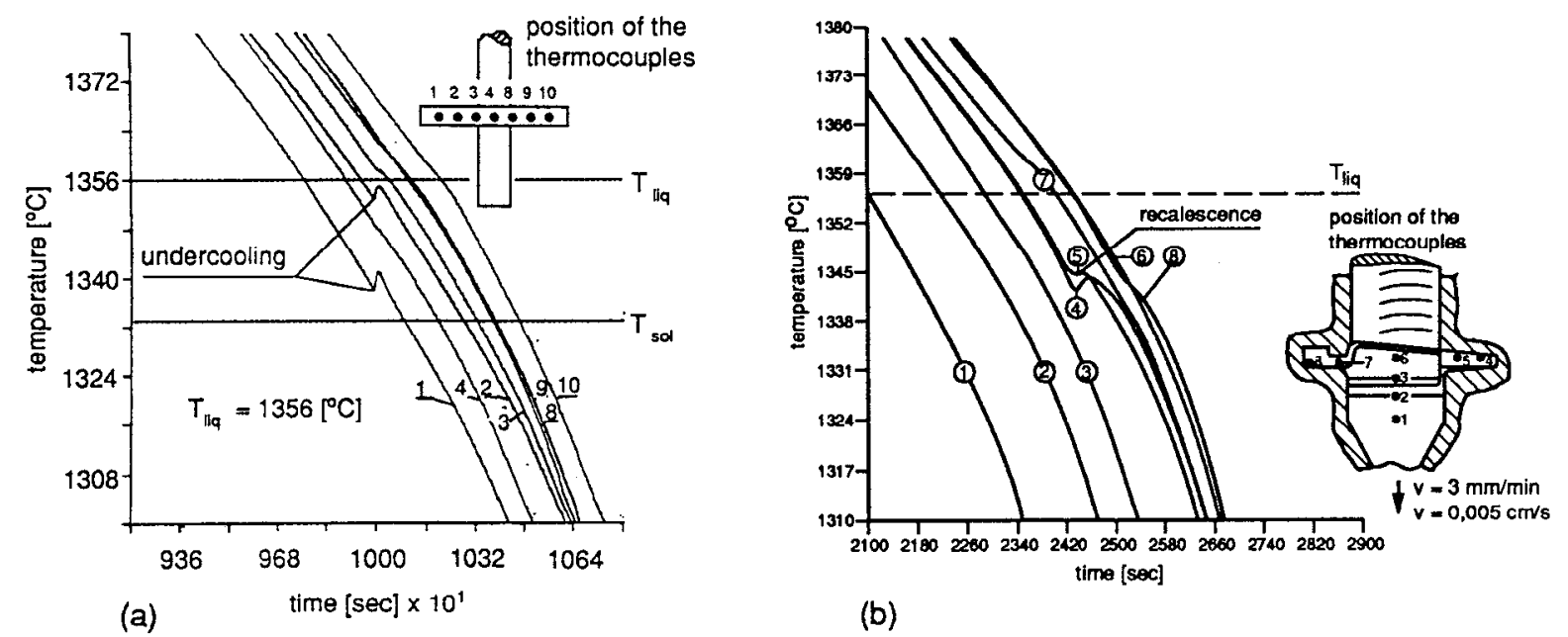

(b)

Figure 5: Cooling curves for dummy (a) and actual (b) turbine blades (SRR99), measured by thermocouples located in platform and vicinity. Platform regions facing central runner of mould show recalescence

Thus, the unidirectional heat transfer temporarily interrupts, possibly resulting in partial remelting of small dendrite arms or heterogeneous nucleation in the remaining interdendritic melt, which will lead to narrow grains - called zebras [7] - occuring in the interdendritic region. These zebras resemble piano keyboards, beeing arranged in adjacent parallel lines (Figure 6). 


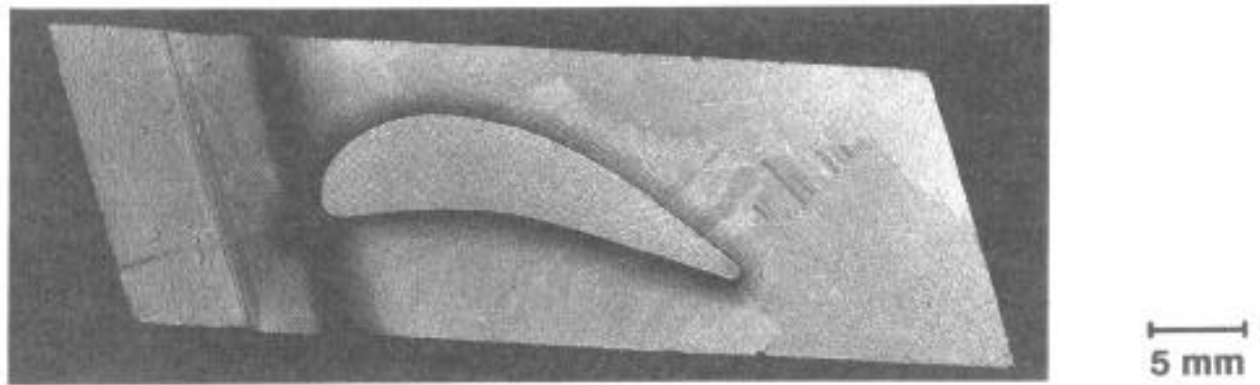

Figure 6: Top view of turbine blade platform showing zebra-grains

During further solidification vertical heat flux in the platform again becomes dominant, and tertiary dendrites grow perpendicular to the lateral secondary dendrites.

The sudden change in both growing direction and speed in the root-to-platform transition causes the single-crystal lattice to be distorted (mosaic structure). This is due to the locally different growing conditions for the face-centered cubic crystals (Figure 7).
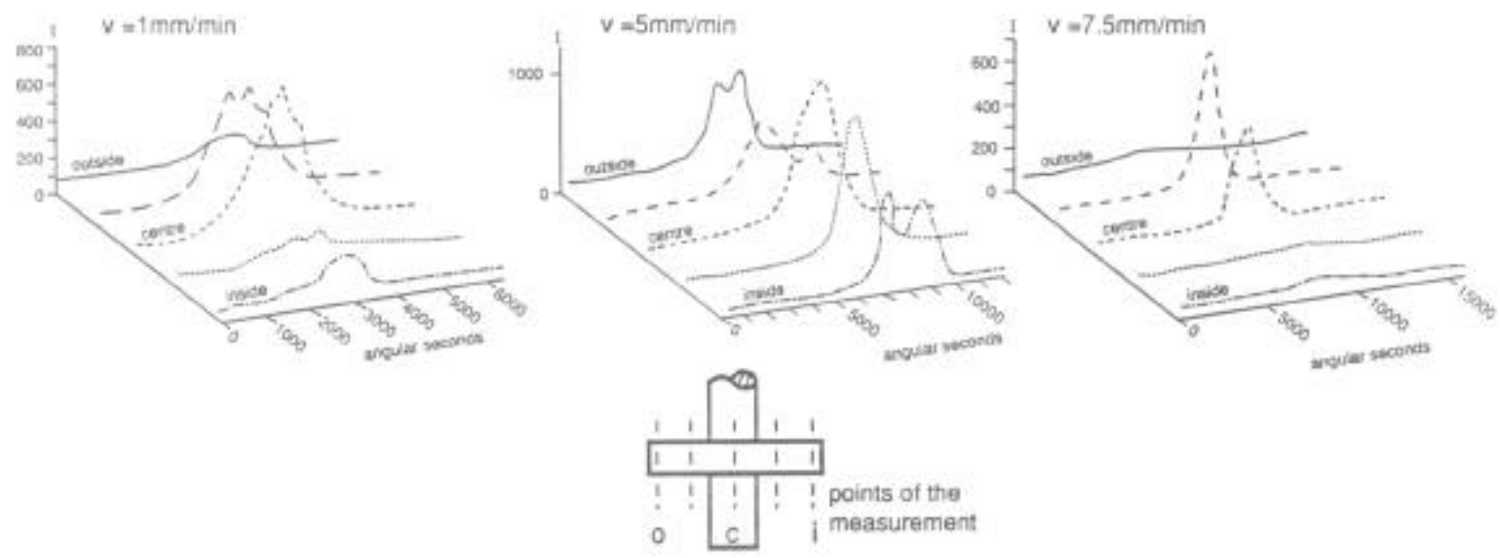

Figure 7: Rocking curves for the platform region of dummy turbine blade at different withdrawal rates determined by $\gamma$-diffractometric measurements (SRR99)

High withdrawal rates ( $v \geq 7,5 \mathrm{~mm} / \mathrm{min}$ ) in particular intensify this effect. This distortion is released by dislocation movement during heat treatment which increases the risk of recrystallization.

Withdrawal rates greater than $5 \mathrm{~mm} / \mathrm{min}$ increase the undercooling in the outer platform regions, resulting in extensive heterogeneous nucleation.

A convex curvature of the liquidus isotherm leads to extensive open microporosity in the platform's upper surface. This occurs particularly when the platform region faces the graphite heater and the withdrawal rate is low ( $v \leq 2 \mathrm{~mm} / \mathrm{min}$ ). Conventional gravity massfeeding is blocked and interdendritic feeding parallel to primary and secondary dendrites is impeded [8]. The volume shrinkage ( 1 to $3 \%$ ) occuring during liquid-solid transition cannot be completely compensated. This is the reason why finally solidified interdendritic sections reveal extensive clusters of open porosity. A low metallostatic pressure of the melt intensifies this effect. 
A concave curvature, on the other hand, provides sufficient mass and interdendritic feeding to prevent open porosity. Normally, this can be accomplished by means of high withdrawal rates ( $\mathrm{v} \geq 4 \mathrm{~mm} / \mathrm{min}$ ). However, the platform region facing the runner rod is heatcd mainly by indirect radiation because of the mould's shadow. Therefore, even low withdrawal rates produce concave curvatures, thereby reducing the amount of microporosity (Figure 8) [9].
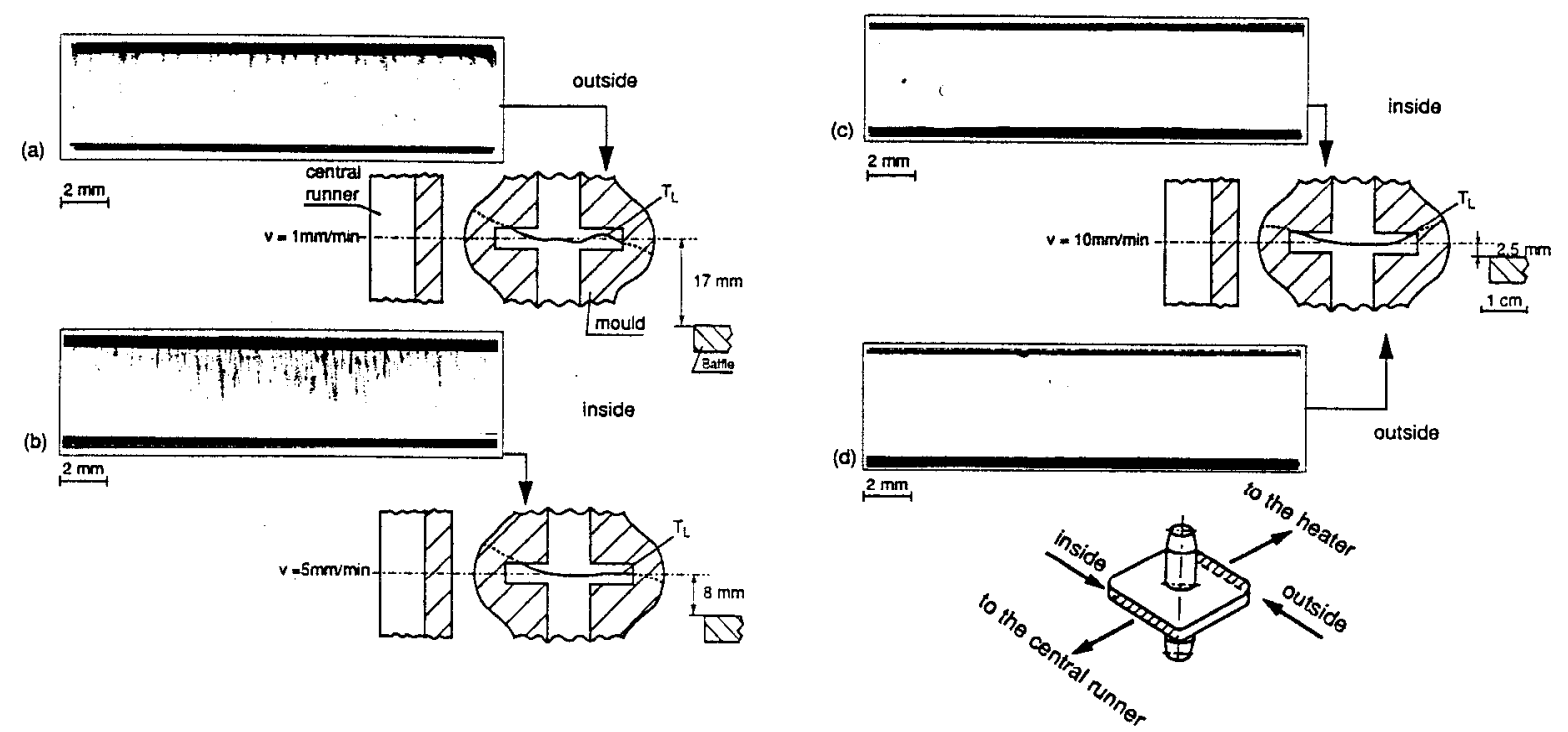

Figure 8: Micropore formation in platform region of dummy turbine blade at various withdrawal rates (SRR99)

It must be taken into account that a concave liquidus isotherm increases the risk of heterogeneous nucleation.

The correlation between the process parameters (withdrawal rate, temperature gradient) and the pressure drop of the melt in the interdendritic region, which represents the proneness to pore formation and which was deduced by J.DAOXIN et al. [10], could not be verified by our experiments.

Because of the extreme difference between the thermal expansion coefficients of the metal and the ceramic mould, the cooling of the component in the mould from solidus to room temperature leads to cracking of the mould and/or plastic deformation of the component, especially at cross-section transitions. Although recrystallization occured in the experiments, a dependence on withdrawal rate or position (i.e. areas specifically facing the heater or runner rod) was not evident within the investigated parameter range. For a given component geometry and shell system, recrystallization is influenced mainly by the temperature of the $\gamma$ 'solutioning heat treatment. (Another means of influencing recrystallization is the modification of shell stiffness by, e.g. applying temporary binder additions to the slurry, which would be burned out during firing and therefore weaken the ceramic mould.)

\section{Recrystallization during $\gamma^{\prime}$-solutioning}

Heating of the surface-deformed CMSX-6 specimens to just below the $\gamma$ '-solvus or to the region of partial $\gamma^{\prime}$-solutioning leads to nucleation of a fine layer of recrystallized grains. 
This layer is confined to the highly deformed area (Figure 9a).

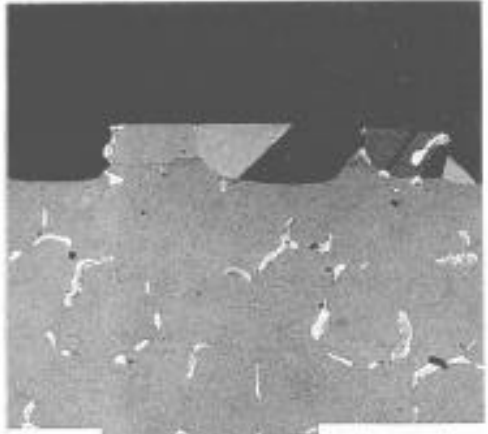

(a)

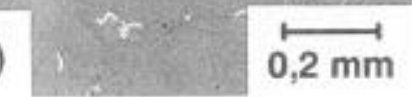

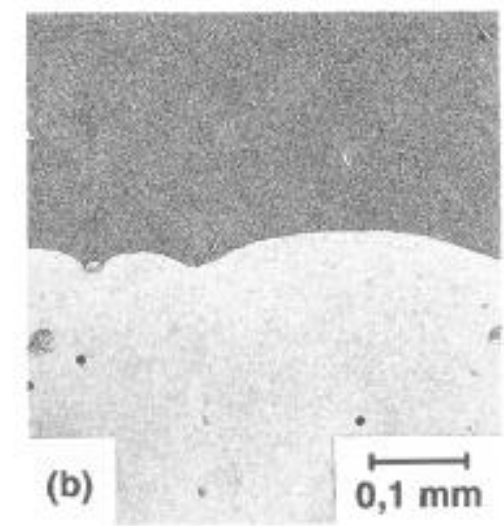

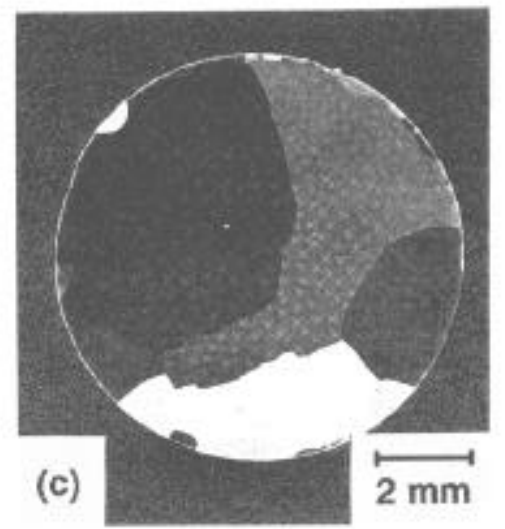

Figure 9: Recrystallization in surface-deformed CMSX-6 specimens during $\gamma^{\prime}$-solutioning

At temperatures at which all the $\gamma^{\prime}$ is brought into solution, some of the very small nucleated grains grow into the undeformed part of the specimen. Migrating grain boundaries are pinned by microstructural inhomogeneities such as residual eutectics or pores (Figure $9 b$ ). Therefore, at temperatures at which residual $\gamma / \gamma^{\prime}$-eutectic is still present, grain growth remains limited. Recrystallization extends over the total specimen cross-section when all $\gamma / \gamma^{\prime}$ eutectic is brought into solution (Figure 9c). Rapid heating to temperatures at which incipient melting occurs reduces the growth rate again, the molten areas acting as obstacles for grain boundary migration. This is demonstrated in Figure 10, which shows the recrystallized volume in CMSX-6 specimens surface-deformed with a hardness tester as a function of the solutioning temperature in comparison with the amount of residual eutectic present after the heat treatment. Limits for full $\gamma^{\prime}$-solutioning and first incipient melting are also indicated. The total heat treatment time was 4 hours; the heating rate between $1200^{\circ} \mathrm{C}$ and final temperature was $5 \mathrm{~K} / \mathrm{min}$, the cooling rate from final temperature approximately $150 \mathrm{~K} / \mathrm{min}$.

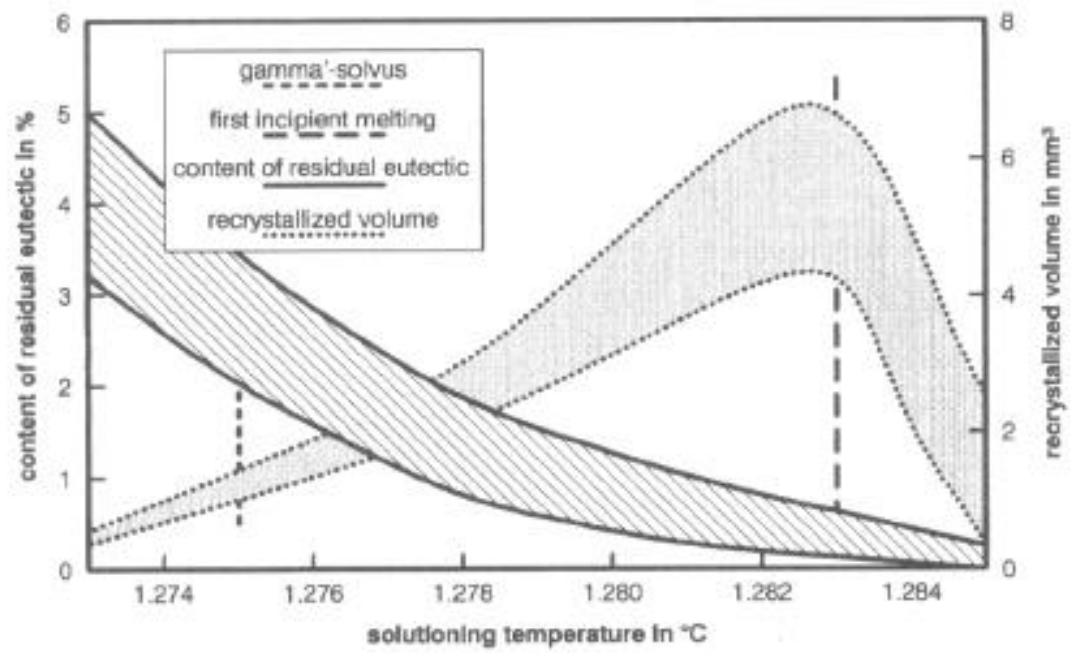

Figure 10: Recrystallized volume in CMSX-6 specimens surface-deformed with a hardness tester as a function of the solutioning temperature in comparison with residual $\gamma / \gamma^{\prime}$-eutectic present after heat treatment 
The reasons (driving forces) for this so-called "excessive recrystallization" are yet not fully understood and require further examination.

HCF-strength of specimens with recrystallized grains or porosity clusters

High-cycle fatigue strength of CMSX-6 specimens containing recrystallized areas of up to $2 \mathrm{~mm}$ in diameter and of CMSX-6 specimens containing porosity clusters is reduced to one half the fatigue strength of the defect-free material (Figure 11).

(a)

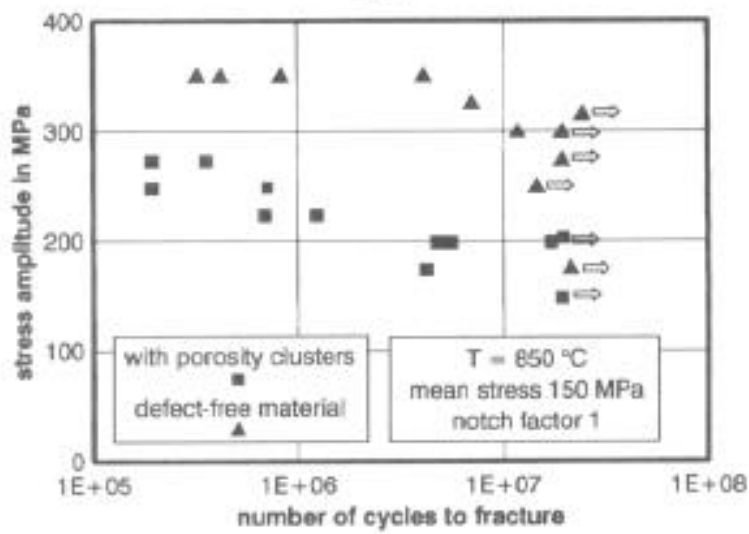

(b)

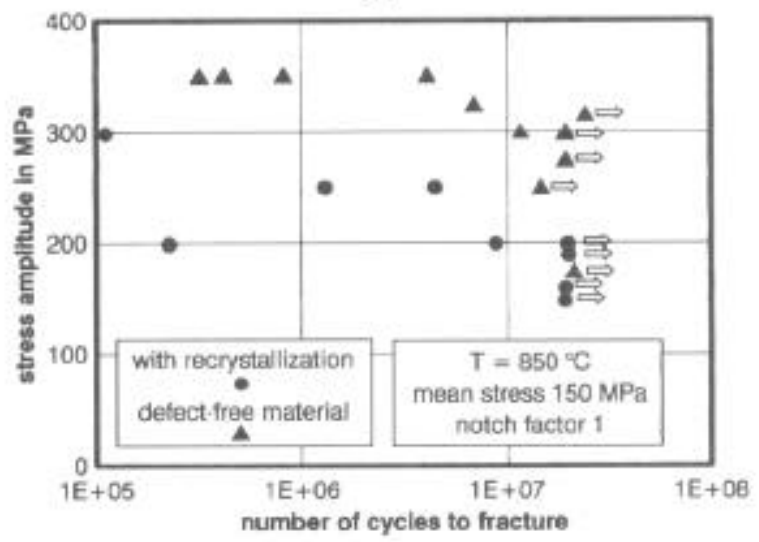

Figure 11: HCF-strength of CMSX-6 specimens containing porosity clusters (a) or recrystallized grains (b) in comparison with defect-free material

In the specimens containing porosity clusters, cracks initiate at the edges of the pores (Figure 12a). Since the individual pores which are caused by shrinkage have a length of up to several millimeters, pore size is of no particular importance. High-cycle fatigue strength has dropped to a low level, but is independent of pore size.

In the specimens containing recrystallized areas grain boundaries crack after very few cycles, and the recrystallized material may even break away completely (Figure 12b). The lifelimiting crack initiates at the edge caused by the loss of the recrystallized grain or grain cluster, and propagates in a plane perpendicular to the loading direction (Figure 12c).
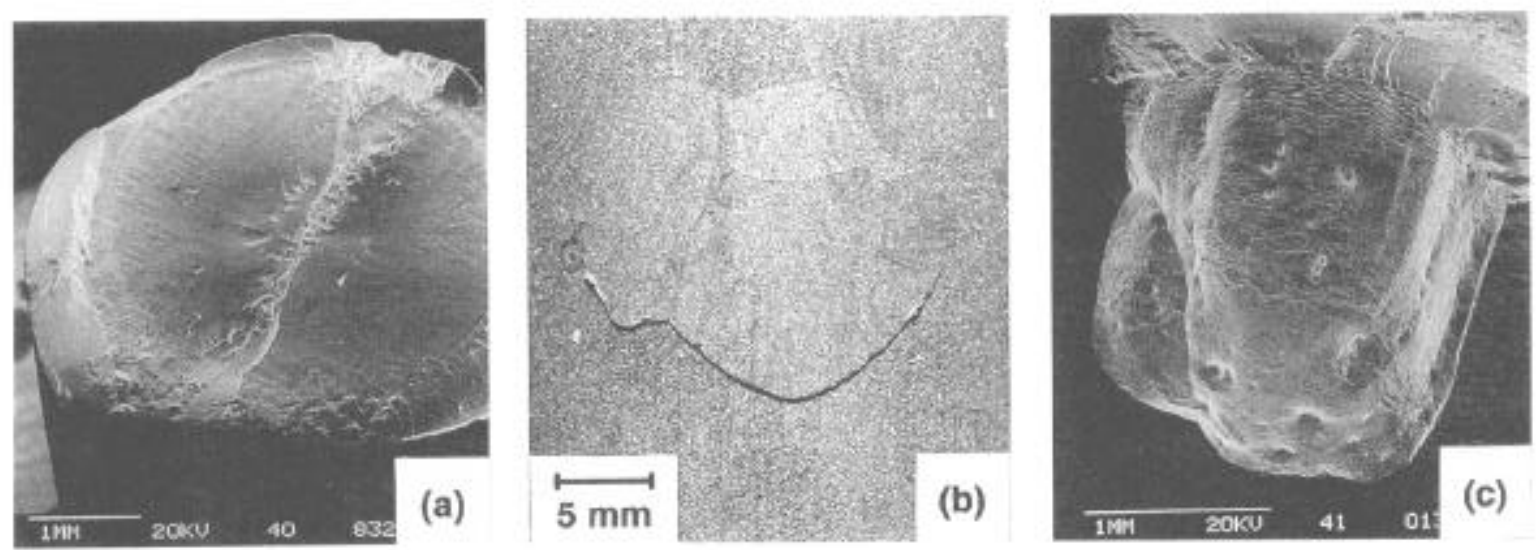

Figure 12: Damage in HCF-specimens at porosity clusters (a) and recrystallized grains (b, c) 


\section{Conclusion}

The formation of porosity clusters depends on the curvature of the liquidus front; the curvature of the liquidus front, in turn, depends on the front's location in the mould and the withdrawal rate. Therefore, rotating the component around its longitudinal and/or transversal axis is an effective measure to relocate porosity clusters from high-stress regions to low-stress regions. In a mould assembly such as the one investigated in this study the more highly stressed platform regions should be moved towards the central runner rod. Another possibility would be to set feeders, but this measure would generate additional costs in series production.

For a given component geometry and shell system, recrystallization is influenced mainly by the temperature during $\gamma^{\prime}$-solutioning heat treatment. A fully solutioned microstructure gives rise to excessive growth of small grains which have nucleated in the deformed areas. For a given application the lowest possible solutioning level is the best choice. Weakening of the shell would be an alternative, but this could lead to problems with geometrical accuracy.

Porosity clusters and recrystallization can be tolerated in these component regions where a lower level of strength is still sufficient. For example, it was found that, at $850^{\circ} \mathrm{C}$, porous CMSX-6 specimens as well as specimens with recrystallized grains still have approximately one half the high-cycle fatigue strength of the defect-free material.

\section{$\underline{\text { References }}$}

1. M.J. Goulette, P.O. Spilling and R.P. Arthey (Paper presented at the 5th Intern. Symposium on Superalloys, Seven Springs, 7-11 Oct. 1984), 167-176.

2. L. Ouichou, G. Lesoult, G. Lamanthe, R. Hamer, J.M. Theret and E. Bachelet (Paper presented at the conference on High Temperature Alloys for Gas Turbines and Other Applications, Lic̀gc, 4-6 Oct. 1982), 955-971.

3. J. Lecomte-Beckers (Paper presented at the 6th Intern. Symposium on Superalloys, Seven Springs, 18-22 Sept. 1988), 713-721.

4. L.G. Fritzemeier (Paper presented at the 6th Intern. Symposium on Superalloys, Seven Springs, 18-22 Sept. 1988), 265-274.

5. U. Paul, P.R. Sahm, A. Donner, D. Goldschmidt and P.D. Portella (Paper presented on the 2nd Symposium Materialforschung, Dresden, 27-29 Aug. 1991), 841-864.

6. U. Paul (Ph.D. thesis, Foundry Institut, Technical University Aachen, Germany, 1992).

7. J.K. Bennet, "Metallurgical Aspects of S.C. Blade Production" (Paper presented at the Symposium on Single-Crystals for Turbine Blades, MTU München, 6-7 June 1989).

8. J. Campbell, The British Foundrysman, 62 (1969), 4.

9. S. Morimoto, A. Yoshinari and E. Niyama (Paper presented at the 5th Intern. Symposium on Superalloys, Seven Springs, 7-11 Oct. 1984), 177-184.

10. J. Daoxin, J. Lecomte-Beckers and L. Habraken, Met. Rep. C.R.M., 59 (1982), 25-34. 